\title{
Assignment of rainfall confidence values using multispectral satellite data at mid-latitudes: first results
}

\author{
T. Nauss ${ }^{1}$ and A. A. Kokhanovsky ${ }^{2}$ \\ ${ }^{1}$ Laboratory of Climatology and Remote Sensing, University of Marburg, Germany \\ ${ }^{2}$ Institute of Remote Sensing, University of Bremen, Germany
}

Received: 2 August 2006 - Revised: 12 December 2006 - Accepted: 26 January 2007 - Published: 26 April 2007

\begin{abstract}
The authors propose a new method for the assignment of rainfall confidences on a pixel basis using cloud properties derived from optical satellite data during daytime. This approach is based on the concept model that the probability for precipitation is a function of the liquid water path, which in turn can be computed using the satellite-retrieved cloud optical thickness and the cloud effective droplet radius. In order to evaluate the principal potential of this idea, scenes from the Terra-MODIS sensor during the severe European summer floods in 2002 have been analysed in order to derive a corresponding regression function that interlinks the liquid water path with the rainfall probability or better with the confidence that a pixel which is classified as raining does actually rain. A first evaluation against ground-based radar data during March 2004 shows good skill of this new method.
\end{abstract}

\section{Introduction}

Rainfall is a key factor in the hydrological cycle and detailed knowledge of the spatio-temporal distribution of precipitation is crucial for hydrological models, for instance. In addition, such information can further improve the reliability of short-term forcasting and nowcasting applications. Over the past decades, many rainfall retrievals based on optical and/or microwave satellite sensors have been developed (Levizzani et al., 2002) but with respect to the use of optical sensors, the techniques are of limited use at high latitudes since the commonly used connection between cloud top temperature and rainfall occurrence is only valid for deep convection but not for stratiform cloud bands within mid-latitude frontal systems (Levizzani et al., 2001; Levizzani, 2003).

Correspondence to: T. Nauss

(nauss@lcrs.de)
In order to overcome this problem, some authors propose the use of a fixed threshold value of the effective cloud droplet radius to discriminate between raining and non-raining cloud areas (e.g. Rosenfeld and Gutman, 1994; Lensky and Rosenfeld, 1997; Ba, 2000). This parameter is defined as the ratio of the third to the second moment of the cloud droplet spectrum (Hansen and Travis, 1974). Recent studies however show that for a reliable detection of precipitating clouds variable threshold values of cloud properties should be used (e.g. Lensky and Rosenfeld, 2003,a; Nauss and Kokhanovsky, 2006). Moreover, research projects have been initiated in order to provide not only dichotomous information on the rainfall area (i.e. rainfall, no rainfall), to which rainfall intensities can be assigned in a second step, but also to estimate the actual precipitation confidence level. This is especially important for the use of such retrieval results in numerical models (e.g. Thoss et. al., 2001; SMHI, 2005). With this in mind, the authors propose the use of the liquid water path as an indicator for the rainfall confidence on a pixel basis.

\section{Assignment of the rainfall confidence level as a func- tion of the liquid water path}

Due to the very homogeneous spatial distribution of the cloud top temperature $T$ for (warm) stratiform frontal clouds with values of $T$ not differing significantly between raining and non-raining regions, the authors have proposed to use an auto-adaptive threshold value of the effective cloud droplet radius $\left(a_{e f}\right)$ with respect to the corresponding value of the optical thickness $(\tau)$ in order to identify both convective and stratiform precipitating cloud areas at mid-latitudes (Nauss and Kokhanovsky, 2006). This idea is based on the concept that rainfall is favoured by both sufficiently large droplets that can fall easily against updraft wind fields and a minimum vertical cloud extent that allows droplets to grow

Published by Copernicus GmbH on behalf of the European Geosciences Union. 


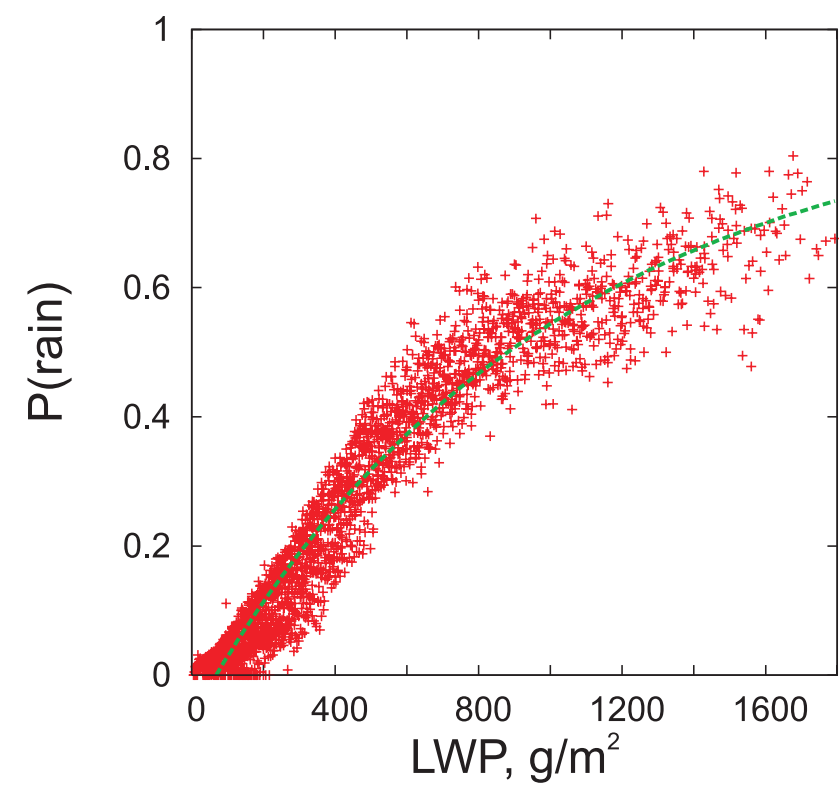

Fig. 1. Rainfall confidence as a function of the liquid water path derived from the comparison of 15 Terra-MODIS scenes between 1 and 15 August 2002 with radar network data from the German weather service over Germany.

and prevents them from evaporating below the cloud bottom (which in turn has an influence on the required droplet size; see also Lensky and Rosenfeld, 2003,a).

For the retrieval of $a_{e f}$ and $\tau$, the Semi-Analytical CloUd Retrieval Algorithm (SACURA, Kokhanovsky et al., 2003; Kokhanovsky and Nauss, 2005) has been applied to visible and near-infrared data from the Moderate Resolution Imaging Spectroradiometer (MODIS, http://modis.gsfc.nasa.gov/) aboard NASA's Terra and Aqua satellites, with a spatial resolution of $1 \mathrm{~km}$. SACURA has been validated over sea and land surfaces against the commonly used look-up table approaches of the Japanese Space Agency JAXA (Nakajima and Nakajima, 1995; Kawamoto et al., 2001) and the NASA MODIS cloud property product MOD06 (Platnick et al., 2003) showing good agreement for optically thick (i.e. raining) cloud systems (Nauss et al., 2005; Kokhanovsky et al., 2006).

For the computation of rainfall confidence values, the spatial distribution of the satellite-derived cloud properties has been compared to corresponding ( $+/-7$ min time difference) ground-based radar data provided by the German weather service (DWD) for 15 MODIS scenes over Central Europe taken during the extreme summer floods in August 2002. This time frame was chosen because it includes a large variety of precipitation processes typical for mid-latitude cyclones. In this context, the rainfall confidence represents the percentage value of pixels with a certain combination of $a_{e f}$ and $\tau$ that have been identified as raining by the radar data.
In order to derive a function for the assignment of rainfall confidence values based on the retrieved cloud properties, the liquid water path

$L W P \approx 2 / 3 \cdot \rho \cdot a_{e f} \cdot \tau$

is used instead of $a_{e f}$ and $\tau$ in order to simplify the regression function ( $\rho$ is the density of water). The resulting relationship between rainfall confidence and the $L W P$ is shown in Fig. 1. The squared correlation coefficient $\left(r^{2}\right)$ reaches 0.91 .

For the final computation of the rainfall confidence values as a function of the $L W P$ an exponential equation according to

$P($ rain $)=\left(1-\exp \left(p_{1} * L W P+p_{2} * L W P^{2}\right)\right)+p_{3}$

is used along with the coefficient values of $-9.936 \times 10^{-4}\left(p_{1}\right), 5.450 \times 10^{-8}\left(p_{2}\right)$, and $-6.526 \times 10^{2}$ $\left(p_{3}\right)$. LWP as shown in Eq. (2) is measured in $\mathrm{g} / \mathrm{m}^{2}$. The residual standard error of this fit is 0.0534 and the run of the function can be seen as the dotted green line in Fig. 1.

Please note that for the present study, ice cloud properties are not considered explicitly. This is due to the fact that the retrieved effective ice chrystal radius is significantly biased by the assumed chrystal shape so that it can not generally be regarded as more accurate. In addition, an explicit consideration of the ice phase does not solve the problem of mixed-phased clouds. After all, since the rainfall confidence is statistically linked with the retrieved cloud properties, the error in assuming water cloud properties can be neglected in the context of this first case study. Nevertheless, with respect to the promising results (see Sect. 3) and appropriate retrieval algorithms at hand (Platnick et al., 2003; Kokhanovsky and Nauss, 2005), we plan to extend this work to the case of ice phase clouds in the near future.

\section{First evaluation of the rainfall confidence assignment}

To get a first impression of the performance of Eq. 2, the rainfall confidence for 28 Terra-MODIS scenes from March 2004 over Germany (morning overpasses) was computed. For every MODIS scene, eight dichotomous datasets (rain/no-rain) were prepared using a different threshold value of the rainfall confidence between 0.1 and 0.8 (step 0.1) for the delineation of the rainfall area. Consequently, these eight datasets show a different extent of the rainfall area with smaller rainfall areas for high threshold values (i.e. 0.7 or 0.8 ) and larger areas for lower threshold values (i.e. 0.1, 0.2). Each of these dichotomous products was then compared to the ground-based radar data rainfall product of the German weather service (DWD) on a $1 \mathrm{~km}^{2}$ basis over Germany (937.204 pixels/scene). All radar pixels with a reflectivity greater/equal $7 \mathrm{dBZ}$ (i.e. DWD radar class 1) with an approximated rain rate larger than $0.06 \mathrm{~mm} / \mathrm{h}$ are considered as precipitating. The probability of detection (POD) and the probability of false detection 
(POFD) were computed. Both scores are based on the number of pixels that have been identified in the satellite (S) and radar (R) techniques as raining $\left(S_{y}, R_{y}\right)$ or non-raining $\left(S_{n}\right.$, $\left.R_{n}\right)$. The POD gives the fraction of the satellite derived rainfall events that have been correctly identified according to the radar product $\left(S_{y} R_{y} / R_{y}\right)$ and the POFD the fraction of the events incorrectly identified as rainfall events by the satellite algorithm $\left(S_{y} R_{n} / R_{n}\right)$. Since the POFD can be artificially decreased by increasing the number of non-raining pixels, only those pixels that have been identified as cloudy by the MODIS cloud mask (MOD035; Ackermann et al., 1998) are considered. The mean cloud fraction within the scenes used in this evaluation is $76 \%$ (with $50 \%$ of the scenes exceeding a cloud fraction of $87 \%$ ).

Figure 2 shows a comprehensive overview of the resulting POD and POFD values using a relative operation characteristic (ROC) plot (Mason, 1982; Jolliffe and Stephenson, 2003). The dotted diagonal line represents the "no skill" line (i.e. POD equals POFD); value combinations above this line indicate that the approach has skill (i.e. POD larger than POFD). Each red line represents the results of one MODIS scene. The crosses within each of these lines show the value combination for one of the dichotomous datasets with the highest probability threshold value $(0.8)$ at the (lower) left end and the lowest probability threshold value $(0.1)$ at the (higher) right end (see also the probability thresholds printed along the blue line). The new approach seems to have good overall skill since the red curves remain clearly above the "no skill" line except for four events that can be identified by straight red lines above or slightly below the "no skill" diagonal. All four of these scenes exhibit only a rainfall area between $0.02 \%$ and $0.23 \%$ so that slight absolute deviations between the number of raining pixels in the satellite and the radar dataset have a large impact on the resulting scores. Generally, the $30 \%$ to $40 \%$ rainfall confidence threshold value seems to be the one with the highest skill (i. e. the most suitable for a yes/no rainfall decision) since the corresponding value combinations show the largest distance normal to the "no skill" line. This is also indicated by the green line, which represents the mean POD and POFD values for every rainfall confidence level.

\section{Conclusions}

A new technique for the assignment of rainfall confidence values at daytime has been presented. It is based on the assumption that cloud liquid water path is directly proportional to the rainfall confidence on a single pixel basis. The function for the computation of the rainfall confidence was derived by a comparison between the rain area detected by ground-based radar stations and the corresponding liquid water path distribution within the satellite scenes. A first statistical evaluation shows that the new approach has skill but beside these promising results, an upcoming and more compre-

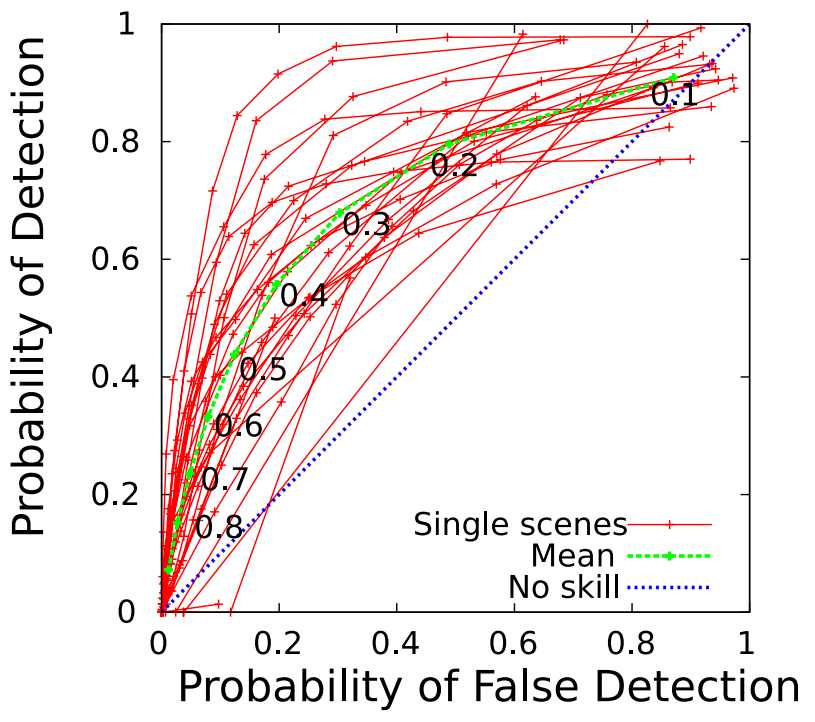

Fig. 2. Relative operating characteristic plot based on the comparison of 28 Terra-MODIS scenes with corresponding ground based radar measurements for cloudy pixels over Germany. Different rainfall confidence threshold values between 0.1 and 0.8 (step 0.1 ) indicated by the crosses and printed along the greenline were used to delineate the satellite-based rainfall area.

hensive study is necessary for a final validation. Moreover, with correspondent retrieval algorithms are in place (Platnick et al., 2003; Kokhanovsky and Nauss, 2005), we plan to extend this work to the case of ice and mixed water clouds in the near future.

Acknowledgements. This work was supported by the German Federal Ministry for Eduaction and Research (BMBF) in the scope of the GLOWA-Danube project 97 GWK 04 "Rainfall Retrieval", the DFG Project BU 688/8-2 and the Erich-Becker foundation (formerly Frankfurt Airport foundation), Germany.

The authors are grateful to J. Bendix, J. P. Burrows, and J. Cermak for valuable discussions, the NASA MODIS team for providing direct broadcast satellite data, and the German weather service (DWD) for providing the radar datasets within the Eumetsat/DWD Advanced Multisensor Precipitation Experiment (AMPE).

Edited by: S. C. Michaelides and E. Amitai

Reviewed by: anonymous referees

\section{References}

Ackermann, S. A., Strabala, K. I., Menzel, W. P., Freey, R. A., Moeller, C. C., and Gumley, L. E.: Discriminating clear sky from clouds with MODIS, J. Geophys. Res., 103, 141-157, 1998.

Ba, M. B.: Routine rainfall estimation from geostationary satellite, in: The 2000 Eumetsat Meteorological Satellite Data Users' Conference, edited by: Eumetsat, Eumetsat Proceedings, Eumetsat, Eumetsat, Bologna, 2000. 
DWD: Weather radar network, available online at http: //www.dwd.de/en/Technik/Datengewinnung/Radarverbund/ Radarbroschuere_en.pdf, 2005-11-07.

Hansen, J. E. and Travis, L. D.: Light scattering in planetary atmospheres, Space Sci. Rev., 16, 527-610, 1974.

Jolliffe, I. T. and Stephenson, D. B.: Forecast Verification. A Practitioner's Guide in Atmospheric Science, Wiley and Sons Ltd, 240 pp, 2003.

Kawamoto, K., Nakajima, T., and Nakajima, T. Y.: A global determination of cloud microphysics with AVHRR remote sensing, J. Climate, 14, 2054-2068, 2001.

Kokhanovsky, A. A. and Nauss, T.: Satellite-based retrieval of ice cloud properties using a semi-analytical algorithm, J. Geophys. Res. - Atmos., 110/D19, D19206, doi:10.1029/2004JD005744, 2005.

Kokhanovsky, A. A., Rozanov, V. V., Zege, E. P., Bovensmann, H., and Burrows, J. P.: A semi-analytical cloud retrieval algorithm using backscattered radiation in 0.4-2.4 micrometers spectral range, J. Geophys. Res., 108(D1), 4008, doi:10.1029/2001JD001543, 2003.

Kokhanovsky, A. A., Rozanov, V. V., Nauss, T., Reudenbach, C., Daniel, J. S., Miller, H. L., and Burrows, J. P.: The semianalytical cloud retrieval algorithm for SCIAMACHY. I. The validation, Atmos. Chem. Phys., 6, 1905-1911, 2006, http://www.atmos-chem-phys.net/6/1905/2006/.

Lensky, I. M. and Rosenfeld, D.: Estimation of precipitation area and rain intensity based on the microphysical properties retrieved from NOAA AVHRR data, J. Appl. Meteorol., 36, 234-242, 1997.

Lensky, I. M. and Rosenfeld, D.: A night-rain delineation algorithm for infrared satellite data based on microphysical considerations, J. Appl. Meteorol., 42, 1218-1226, 2003.

Lensky, I. M. and Rosenfeld, D.: Satellite-based insights into precipitation formation processes in continental and maritime convective clouds at nighttime, J. Appl. Meteorol., 42 , 1227-1233, 2003.

Levizzani, V., Amorati, R., and Meneguzzo, F.: A review of satellite-based rainfall estimation methods, European Commission Project MUSIC Report (EVK1-CT-2000-00058), 66 pp., 2002.
Levizzani, V.: Satellite rainfall estimations: new perspectives for meteorology and climate from the EURAINSAT project, Ann. Geophys., 46, 363-372, 2003, http://www.ann-geophys.net/46/363/2003/.

Levizzani, V., Schmetz, J., Lutz, H. J., Kerkmann, J., Alberoni, P. P., and Cervino, M.: Precipitation estimations from geostationary orbit and prospects for Meteosat Second Generation, Meteorol. Appl., 8, 23-41, 2001.

Mason, I.: A model for assessment of weather forecasts, Australian Meteorlogical Magazine, 30, 291-303, 1982.

Nakajima, T. Y. and Nakajima, T.: Wide-area determination of cloud microphysical properties from NOAA AVHRR measurements for FIRE and ASTEX regions, J. Atmos. Sci., 52, 40434059, 1995.

Nauss, T., Kokhanovsky, A. A., Nakajima, T. Y., Reudenbach, C., and Bendix, J.: The intercomparison of selected cloud retrieval algorithms, Atmos. Res., 78, 46-78, 2005.

Nauss, T. and Kokhanovsky, A. A.: Discriminating raining from non-raining clouds at mid-latitudes using multispectral satellite data, Atmos. Chem. Phys., 6, 5031-5036, 2006, http://www.atmos-chem-phys.net/6/5031/2006/.

Platnick, S., King, M. D., Ackerman, S. A., Menzel, W. P., Baum, B. A., Riédi, J. C., and Frey, R. A.: The MODIS cloud products: Algorithms and examples from Terra, IEEE Transact. Geosci. Rem. Sens., 41, 459-473, 2003.

Rosenfeld, D. and Gutman, G.: Retrieving microphysical properties near the tops of potential rain clouds by multispectral analysis of AVHRR data, Atmos. Res., 34, 259-283, 1994.

Swedish Meteorological and Hydrological Institute (SMHI): Software User Manual for PGE04 of the NWCSAF/MSG: Scientific Part, 27 pp., 2005, available online at http://nwcsaf.inm.es/HTMLContributions_v1.0/SUM/ SAF-NWC-IOP-SMHI-SCI-SUM-04_v1.2.pdf, 2006-06-21.

Thoss, A., Dybbroe, A., and Bennartz, R.: The nowcasting SAF precipitating clouds product, Proceedings of the 2001 EUMETSAT Meteorological Satellite Data Users' Conference, EUMETSAT, 399-406, 2001. 